\title{
Provendo acesso à solução de conflitos na Economia Digital
}

\section{Promoting access to dispute resolution within the Digital Economy}

\author{
Ana Cândida Muniz Cipriano ${ }^{1}$
}

\begin{abstract}
Resumo: A pandemia provocada pela Covid-19 trouxe uma nova velocidade para as relações de consumo, forçando tanto fornecedores quanto consumidores a se adaptarem à novas formas de consumo, à novos produtos e serviços, enfim, à uma nova realidade. $\mathrm{O}$ acesso à solução de conflitos, ou o simples acesso do consumidor ao fornecedor, no pós venda, não seguiu a mesma velocidade. $O$ presente artigo traz uma reflexão sobre os esforços impulsionados pela economia digital no provimento de plataformas para a solução de conflitos de consumo.
\end{abstract}

Parole chiave: Direito do Consumidor, conflitos de consumo; plataformas on line; economia digital;

Resumo: The pandemic caused by Covid-19 brought a new speed to consumer relations, forcing both suppliers and consumers to adapt to new forms of consumption, new products and services, in short, to a new reality. Access to conflict resolution, or the simple access of the consumer to the supplier, after sales, did not follow the same speed. This article reflects on the efforts driven by the digital economy in providing platforms for resolving consumer conflicts.

Palavras-chave: Consumer Law, consumer dispute, online platforms, Digital Economy.

\section{Introdução}

As Diretrizes das Nações Unidas para a Proteção do Consumidor (Resolução da Assembleia Geral 70/186 de 22 de dezembro de 2015) exigem um mecanismo justo, eficiente, transparente e imparcial para lidar com as reclamações dos consumidores, inclusive em casos transfronteiriços. Os mecanismos tradicionais de solução de litígios relativos às reclamações dos consumidores, de natureza administrativa e judicial, são cada vez mais

\footnotetext{
${ }^{1}$ Doutoranda pela Universidade de Buenos Aires - UBA. Mestre em Direito Internacional e Europeu pela Universidade de Genebra. Diretora Adjunta de Assuntos Internacionais do Instituto Brasileiro de Política e Direito do Consumidor (BRASILCON). Membro da Ordem dos Advogados do Brasil, Seção de São Paulo e da International Law Association, ILA. Legal Officer na Conferência das Nações Unidas para Comércio e Desenvolvimento, UNCTAD (Genebra, Suiça).
} 
complementados por um método alternativo de resolução de litígios (Alternative Dispute Resolution - ADR), quer seja a conciliação, a mediação ou a arbitragem. Uma solução eficaz para fornecer solução alternativa de litígios aos consumidores é o uso de plataformas online.

A resolução de disputas online consiste em mecanismos de resolução de disputas facilitados pelo uso de comunicações eletrônicas e outras tecnologias de informação e comunicação. Esta é uma forma de aumentar a confiança do consumidor no comércio eletrônico, especialmente no comércio internacional.

São interessantes os exemplos de Estados que fizeram esforços significativos para desenvolver mecanismos de resolução de disputas online. Brasil $^{2}$, Colombia ${ }^{3}$ e Mexico $^{4}$ replicaram os serviços de mediação patrocinados pelo estado em contextos online que permitem uma resolução rápida e acessível de disputas online e offline. Após a publicação do regulamento da União Europeia de 21 de maio de 2013 sobre solução de litígios online para conflitos de consumo, a Comissão Europeia também criou um portal ${ }^{5}$. A Associação das Nações do Sudeste Asiático (ASEAN) planeja criar uma plataforma regional de resolução de conflitos online até 2025 (ASEAN, 2016).

Mercados eficientes são essenciais para o sucesso da implementação da Agenda de Desenvolvimento Sustentável 2030. Os mercados desempenham um papel importante na alocação de recursos. No entanto, sem mecanismos regulatórios apropriados, há riscos de falha de mercado, incluindo abuso de poder de monopólio, externalidades negativas e desigualdades. A pandemia causada pela Covid-19 intensificou tanto o desenvolvimento da Economia Digital quanto as vulnerabilidades de consumidores e pequenos empresários em um cenário de escassez e crise.

\footnotetext{
${ }^{2}$ Site da Autoridade brasileira de ODR: https://www.consumidor.gov.br/

${ }^{3}$ Site da Autoridade Colombiana de ODR: http://sicfacilita.sic.gov.co/SICFacilita/

${ }^{4}$ Site da Autoridade Mexicana de ODR: https://concilianet.profeco.gob.mx

${ }^{5}$ Site da União Europeia de ODR: https://ec.europa.eu/consumers/odr/main
} 
Os consumidores de hoje, consumidores da era digital, exigem não apenas acesso rápido, eficiente e transparente a produtos e serviços, mas também a fornecedores, informações e resolução de conflitos. É possível criar plataformas de resolução de conflitos de consumo sem a participação do Estado? É necessário o envolvimento do Estado, ou ainda, é mesmo relevante a sua participação na área de resolução de disputas de consumo? Qual é o futuro da Solução de Conflitos Online de Consumo (CODR, na sigla em inglês, Consumer Online Dispute Resolution)?

\section{Visão geral histórica e diretrizes das Nações Unidas para a proteção do consumidor}

Historicamente, os direitos do consumidor foram discutidos e reivindicados pela sociedade civil. O movimento de proteção ao consumidor é o resultado de uma série de desenvolvimentos econômicos - o estabelecimento do capitalismo - como um sistema econômico comum baseado na propriedade privada, no acúmulo de capital, no trabalho assalariado, no sistema de preços, nos mercados e distribuição de bens e serviços determinado pela competição de mercado. Toda essa liberdade de mercado exige, portanto, a proteção dos consumidores, cujos direitos são reconhecidos principalmente por sua vulnerabilidade em relação aos fornecedores, aos que vendem bens e prestam serviços.

A primeira organização civil de proteção aos consumidores foi fundada nos Estados Unidos da América (EUA), em 1936. Chamada de Consumer Reports, ela foi "formed as an independent, non-profit organization (...) serves consumers through unbiased product testing and ratings, research, journalism, public education, and advocacy (...)" (CR, s/d). Ademais, contase ainda com um dos mais respeitados representantes da sociedade civil para a proteção do consumidor no mundo, a Consumers International, com sede em Londres e fundada em 1960 com a missão de “(...) champion 




Consumer Rights internationally in order to help protect and empower consumers everywhere (...)" (CI, s/d).

O Tratado sobre o Funcionamento da União Europeia (TFUE) de 1957 (que entrou em vigor em 1958), bem como o Tratado da União Europeia, constituem a base do direito da União Europeia. No que diz respeito à defesa do consumidor (artigo $4^{\circ}$ ), mais precisamente ao abrigo do Título XV, o artigo $169^{\circ}$ (antigo artigo $153^{\circ}$ do Tratado CE) estabelece as bases das políticas europeias de defesa do consumidor: saúde, segurança e interesses económicos dos consumidores, direito à informação e educação.

No entanto, o marco histórico para o reconhecimento dos direitos do consumidor, e o primeiro vislumbre do que seria de fato a política de proteção ao consumidor, é o discurso do ex-presidente dos Estados Unidos da América, John Kennedy, que em 15 de março de 1962, dirigiu-se ao Congresso dos EUA para afirmar:

Consumers by definition, include us all, They are the largest
economic group, affecting and affected by almost every public and
private economic decision. Yet they are the only important group...
whose views are often not heard. (...) Additional legislative and
administrative action is required, however, if the federal
Government is to meet its responsibility to consumers in the exercise
of their rights. These rights include: (1) The right to safety [...] (2)
The right to be informed- -to be protected [information, advertising,
labelling]; (3) The right to choose--to be assured, wherever possible,
access to a variety of products and services at competitive prices
[...]; (4) The right to be heard [consideration of consumer interests
in the formulation of Government policy] and fair and expeditious
treatment in its administrative tribunals. To promote the fuller
realization of these consumer rights, it is necessary that existing
Government programs be strengthened, that Government
organization be improved, and, in certain areas, that new
legislation be enacted (EUA, 1962).

Continuando a linha do tempo, a partir da adoção dos Princípios das Nações Unidas para a Proteção do Consumidor (UNGCP), em 9 de abril de 1985, o movimento do consumidor se fortaleceu ao fornecer um modelo básico para o desenvolvimento de leis e políticas de proteção e defesa dos direitos dos consumidores. As Diretrizes das Nações Unidas para a Proteção 
do Consumidor (UNGCP) reconheceram claramente a importância da proteção dos direitos fundamentais - como instrumento de desenvolvimento econômico - como o direito à segurança, o direito à informação, o direito de escolha e o direito a ser ouvido (NACIONES UNIDAS, 1985).

Mais de quase quatro décadas depois, ainda é difícil garantir alguns direitos básicos do consumidor, como o direito à informação e o direito à segurança (integridade física do consumidor). Nestes tempos de comércio eletrônico e de amplo e fácil acesso a produtos e serviços em todo o mundo, essas preocupações se tornaram ainda mais importantes.

A última reforma das UNGCP (2015) não só confirmou a importância dos direitos do consumidor internacionalmente, mas também estabeleceu a criação de um grupo intergovernamental de especialistas em legislação e política de proteção ao consumidor, que é a referência internacional para a política de direitos do consumidor. O Grupo Intergovernamental de Expertos em proteção ao consumidor e política, IGE Consumer, oferece anualmente um fórum para consultas multilaterais, discussões e trocas de pontos de vista entre os Estados-Membros, especialistas e partes interessadas relevantes. Por atuar no âmbito da Conferência das Nações Unidas sobre Comércio e Desenvolvimento (UNCTAD), o IGE também representa o reconhecimento das questões do consumidor no âmbito das Nações Unidas, em mais de 30 anos de existência, de um conjunto de princípios internacionais que definem as principais características das referências em termos de proteção efetiva do consumidor e legislações como as UNGCP.

No que diz respeito à solução de controvérsias, as Diretrizes das Nações Unidas para a Proteção do Consumidor incentivam os Estados membros a: a) Estabelecer mecanismos para o intercâmbio de informações sobre suas políticas e medidas relativas à proteção do consumidor, ou revisar, manter ou fortalecer os mecanismos existentes, conforme o caso; b) Cooperar ou estimular a cooperação no domínio da aplicação das políticas de 
defesa do consumidor, a fim de obter melhores resultados com os recursos disponíveis.

Como parte dessa cooperação, eles podem, em particular, criar ou usar em conjunto laboratórios, desenvolver procedimentos de análise comuns, trocar informações sobre o consumidor e programas de educação, organizar programas de treinamento comuns e desenvolver regulamentos em conjunto; c) Cooperar para a melhoria das condições de oferta dos bens essenciais aos consumidores, observados o preço e a qualidade. Esta cooperação poderá incluir a compra conjunta de bens essenciais, o intercâmbio de informações sobre as diversas possibilidades de compra e a celebração de acordos sobre especificações de produtos a nível regional (NACIONES UNIDAS, 1985, diretriz n. 79).

As UNGCP reconhecem e incentivam o envolvimento dos Estados Membros na cooperação regional ou sub-regional para fortalecer as trocas de informações sobre produtos proibidos, objeto de recall ou restrições (Princípio 80), proporcionando aos consumidores um ambiente e mercado mais seguros. Além disso, além da relevância de se concentrar na segurança e / ou qualidade dos produtos (Princípios 81 e 82), a cooperação entre os Estados-Membros também oferece uma melhor proteção contra práticas comerciais transfronteiriças fraudulentas e enganosas, um assunto que ganhou relevância desde o desenvolvimento da economia digital, ignorando fronteiras.

Além de proteger os direitos do consumidor, as políticas do consumidor também garantem que os consumidores estejam bem informados para tomar decisões informadas. A aplicação da lei do consumidor, a vigilância do mercado e a informação, comunicação e educação eficazes são consideradas ferramentas básicas, importantes para a defesa dos direitos do consumidor.

É inegável que consumidores informados desempenham um papel determinante na inovação, produtividade e concorrência. Para estimular a 
concorrência, os consumidores precisam de informações objetivas, transparentes, facilmente acessíveis para tomar decisões informadas que melhor atendam às suas necessidades e interesses. Nesse contexto, o empoderamento do consumidor se tornou mais importante nos mercados em rápida mudança, onde surgem produtos e serviços novos e complexos a todo o momento (OECD, 2010). A educação do consumidor pode capacitar os consumidores, facilitando seu acesso às informações e fortalecendo sua capacidade de avaliar as informações de maneira adequada para tomar decisões conscientes, informadas.

No entanto, o que é possível prover em uma economia cada vez mais dinâmica, veloz, diversificada? A crise decorrente da pandemia causada pela COVID-19 não apenas intensificou a Economia Digital, obrigando os mais diversos segmentos a migrarem para plataformas digitais como meio de sobrevivência face às restrições durante a pandemia, mas também obrigou consumidores a se adaptarem à uma nova realidade, incluindo o consumo online nos mais diversos setores da economia. Como proteger esse consumidor em uma economia virtual? Como garantir que as vulnerabilidades enquanto consumidor não sejam exacerbadas? Como prover um sistema de proteção ao consumidor quando uma grande variedade de produtos e serviços estão disponíveis, onde quer que você esteja no mundo? É o sistema de proteção ao consumidor como o conhecemos hoje suficiente para garantir proteção em uma economia digital? Qual o papel do Estado nesse processo?

\section{Solução de Conflitos de Consumo na Economia Digital}

Quando os direitos do consumidor não são respeitados ${ }^{6}$ seja por falta de informação, defeito do produto ou serviço ou mesmo um acidente, o

\footnotetext{
6 "Escopo 2. Estas Diretrizes são aplicáveis às transações entre empresas e consumidores, incluindo o fornecimento de bens e serviços por empresas estatais. (...)" (NACIONES UNIDAS, 1999).
} 
consumidor tende a entrar em contato primeiramente com o fornecedor aquele que vendeu o produto/serviço. É muito raro os consumidores contatarem direta e imediatamente especialistas em proteção ao consumidor, autoridades ou mesmo o fabricante do produto. Na verdade, os consumidores são incentivados pelas autoridades a contatar primeiro o fornecedor, o vendedor do produto ou serviço, quando surge um conflito, um problema.

Normalmente, apenas após entrar em contato com o fornecedor, vendedor do bem ou serviço (e, sendo esse contato infrutífero), os consumidores tendem então a procurar ajuda junto às autoridades de consumo. Normalmente, quando o consumidor faz uma reclamação junto ao órgão de defesa do consumidor, já existe um número considerável de registros de reclamações, seja por telefone ou pessoalmente, a respeito do problema identificado. ${ }^{7}$

Portanto, é importante considerar, e lembrar, que o objetivo e o procedimento para o recebimento de reclamações de consumidores por parte de fornecedores/empresas, não é o mesmo que aquele dos órgãos de defesa do consumidor ou da sociedade civil - em diversos aspectos. Os objetivos pretendidos por órgãos de defesa do consumidor, associações de consumidores (sociedade civil), se concentram na proteção dos direitos do consumidor e na aplicação da legislação de proteção do consumidor. O fornecedor, ao lidar com reclamações de consumidores, tem como meta principalmente a proteção e aperfeiçoamento de seus próprios produtos e serviços.

As UNGCP preveem, no princípio 8, que os Estados-Membros devem criar e manter infraestruturas adequadas para implementar e monitorizar

\footnotetext{
${ }^{7}$ Neste ponto, é útil e importante esclarecer que os serviços prestados aos clientes pelas empresas não proporcionam aos consumidores o mesmo atendimento que os órgãos de defesa do consumidor ou a sociedade civil de defesa do consumidor. Dependendo da função do ombudsman (que originalmente era um defensor dos direitos humanos encarregado de lidar com as solicitações dos cidadãos ou reclamações feitas ao governo), até mesmo o setor privado usa esses números que alteram a neutralidade inicial e o significado do termo "ombudsman"per se.
} 


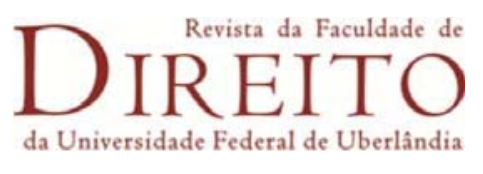

as políticas de proteção do consumidor, especificando também, no princípio 32, a relevância das ferramentas de monitorização ("adequação do mecanismo"). As agências de defesa do consumidor, sejam elas nacionais, locais ou regionais, desempenham um papel muito importante pela sua proximidade com os consumidores e suas realidades, bem como por seus poderes e mecanismos políticos. ${ }^{8}$

Independentemente do modelo do sistema de defesa do consumidor, o importante é garantir a defesa do consumidor, a proteção dos consumidores e fazer cumprir os seus direitos. E permitir aos consumidores reclamar é um dos direitos mais básicos: o direito de ser ouvido, o direito de reclamar e de obter reparação, o direito de acessar informação. Todos esses direitos estão intimamente ligados: os consumidores têm o direito de acessar, facilmente, as informações e reclamar de um produto ou serviço.

Como um direito fundamental do consumidor, - fazer uma reclamação - o acesso aos métodos e canais de reclamação deve ser fornecido não apenas pelos órgãos de defesa do consumidor, mas também por todos os envolvidos na relação de consumo: fornecedores, produtores - ou seja, empresas e associações de consumidores e o setor regulado. Os Princípios das Nações Unidas de Proteção ao Consumidor (NACIONES UNIDAS, 2015) encorajam e apoiam o trabalho e o engajamento de agências de proteção ao consumidor:

8. Os Estados-Membros devem estabelecer ou manter a infraestrutura necessária para desenvolver e implementar políticas de defesa do consumidor e para monitorizar a sua implementação. Deve-se ter cuidado especial para garantir que as medidas de proteção ao consumidor sejam aplicadas em benefício de todos os setores da população, especialmente a população rural $e$ desfavorecida." (Princípio 8); "G) Meios eficazes de resolução de litígios e reparação", (III. Princípios Gerais, g; "15. Os Estados-

\footnotetext{
8 IV. Princípios para governar as práticas comerciais (...) 11. Os princípios a seguir constituem uma estrutura de referência para a condução de atividades comerciais em suas relações comerciais online e offline com os consumidores: f) Reclamações e disputas. As empresas devem disponibilizar aos consumidores mecanismos de reclamação que garantam uma resolução justa, transparente, econômica, acessível, rápida e eficiente de litígios, sem incorrer em custos ou encargos indevidos. Eles devem considerar o respeito aos padrões nacionais e internacionais para revisão de reclamações internas, resolução alternativa de disputas e códigos de satisfação do cconsumidor (NACIONES UNIDAS, 1999).
} 
Membros devem assegurar que os órgãos responsáveis pela defesa do consumidor disponham dos recursos humanos e financeiros necessários para fazer cumprir as normas e obter reparação em nome dos consumidores em casos que justifiquem ou facilitem esta tarefa. (NACIONES UNIDAS, 2015, Princípio n. 15).

Faz sentido que as autoridades de proteção ao consumidor sejam mais capazes de informar, educar, remediar e moldar as políticas de proteção ao consumidor: elas têm experiência para reconhecer e tratar todas as vulnerabilidades do consumidor da forma mais adequada. Consequentemente, os canais de resolução de conflitos de consumo disponibilizados pelas empresas e associações de consumidores devem ser considerados como complementares àqueles disponibilizados pelas autoridades responsáveis pela proteção do consumidor.

Existem diferentes modos de resolver disputas de consumo e obter reparação. O canal tradicional é o canal de reclamações de consumidores, disponibilizado pelas autoridades de defesa do consumidor no âmbito dos procedimentos administrativos. No entanto, além disso, os consumidores também podem buscar reparação nos tribunais. As duas ações judiciais (tribunais) mais comuns são "pequenas causas" e ações coletivas (UNCTAD, 2017) - geralmente não acessível a todos os consumidores por seus custos implícitos, como, por exemplo, não ser fisicamente acessível a todos os consumidores; ou ainda por suas diferenças entre o custo do produto/serviço e as custas judiciais.

Finalmente, algumas referências a métodos alternativos de resolução de disputas e mediação (é importante especificar aqui que os termos relativos à mediação e arbitragem podem variar de um país para outro. $\mathrm{Na}$ Argentina $^{9}$ existe um mecanismo de resolução de litígios denominado "arbitragem", que na realidade é uma mediação realizada pela autoridade de defesa do consumidor. Nos EUA, é possível recorrer à arbitragem de

\footnotetext{
9 Site argentino de solução de litígios: https://www.argentina.gob.ar/produccion/consumidor/sistema-nacional-de-arbitraje-deconsumo
} 
consumo, no Brasil1 (1996) e na Europa (2013) este não é o caso, visto que a arbitragem é limitada a disputas entre fornecedores, ou seja, entre empresas.

$\mathrm{Na}$ verdade, a relação de consumo envolve dois atores principais e diferentes: a empresa (tendo a expertise no bem ou serviço, tendo o poder jurídico e financeiro) e o consumidor (geralmente pressionado a aderir a um contrato padrão pré-estabelecido, sem qualquer expertise técnica a respeito do produto/serviço) e certamente sem nenhum poder financeiro face ao fornecedor. Na verdade, é precisamente devido a desse desequilíbrio de poderes, que a proteção do consumidor é necessária (BENJAMIN; LIMA MARQUES; BESSA, 2013).

No entanto, isso não impede que as próprias empresas ofereçam canais e ferramentas para a solução de conflitos decorrentes da relação de consumo. Na verdade, as empresas são incentivadas e devem fazê-lo:

\begin{abstract}
IV. Princípios que regem as práticas de negócios, dos Princípios das Nações Unidas de Proteção ao Consumidor, f) Reclamações e disputas. As empresas devem disponibilizar aos consumidores mecanismos de reclamação que garantam uma resolução justa, transparente, econômica, acessível, rápida e eficiente de suas disputas, sem incorrer em custos ou encargos indevidos. Eles devem considerar a assinatura de padrões nacionais e internacionais para revisão de reclamações internas, resolução alternativa de conflitos e códigos de satisfação do consumidor (NACIONES UNIDAS, 2015).
\end{abstract}

Fornecer acesso a informações, resolução de conflitos e reparação é uma boa prática comercial. Para obter informações ou resolver uma determinada situação, os consumidores geralmente entram em contato direta e primeiramente com a empresa que lhes forneceu o produto ou serviço. O fornecedor final do produto ou serviço é geralmente o representante mais próximo do consumidor e supostamente o mais fácil de contatar.

Embora se espere que as empresas forneçam aos consumidores canais acessíveis e rápidos para contatálos, os consumidores comumente enfrentam dificuldades, após a aquisição de um produto ou serviço: i. falta de 
informação comercial; ii. falta de informações de contato comercial; iii. canais de comunicação inacessíveis; iv. falta de canais e/ou mecanismos adequados para os consumidores reclamarem. Tais dificuldades são ainda mais evidentes e exacerbadas no comércio eletrônico, levando o consumidor a buscar orientação do segundo contato usual: as autoridades de consumo.

As dificuldades encontradas pelos consumidores em registrar uma reclamação, dirigida a empresas, estão naturalmente ligadas a um direito fundamental do consumidor: o direito à informação. A economia digital tornou muito mais fácil o acesso a bens e serviços, mas e o pós-venda e a resolução de conflitos? O que dizer sobre o acesso ao próprio fornecedor para que os consumidores possam solucionar dúvidas e problemas? Quando os consumidores são forçados a fornecer o máximo possível de informações sobre si mesmos, enquanto as empresas permanecem escondidas atrás de uma página web ou aplicativo?

\section{As novas formas de relação de consumo e a velocidade da Economia Digital}

A quarta revolução industrial está se desenrolando diante de nossos olhos e seu principal combustível é a tecnologia, desenvolvendo uma variedade de canais de negócios eletrônicos. Há uma infinidade de novos produtos e serviços desenvolvidos ou atualizados pelo comércio eletrônico, pelo mundo virtual. Podemos ter acesso a produtos virtuais e até dinheiro.

Pessoas em todo o mundo têm acesso instantâneo a bens e serviços, mas o comércio internacional floresceu ao máximo graças aos avanços nas telecomunicações, possibilitando o que hoje chamamos de economia digital: produtos e serviços virtuais, roupas, livros, jornais e serviços financeiros. Sem falar nas novas formas de comunicação e comércio graças às plataformas de redes sociais que foram desenvolvidas.

O advento da economia digital trouxe uma variedade - não só de produtos e serviços - mas, sobretudo, novos canais de consumo. Em qualquer 
parte do mundo, cada vez mais consumidores têm acesso a produtos e serviços que, há cerca de 30 anos, eram acessíveis apenas a um seleto grupo da sociedade (pelo menos em países em desenvolvimento).

Além disso, os avanços tecnológicos também criaram novas formas de relações de consumo: hoje em dia, consumidores agem como empresas e empresas são vistas como consumidoras. Novas plataformas onde o cidadão comum, sem qualquer expertise em negócios ou sem atividade profissional específica, está se tornando cada vez mais uma fonte de renda adicional: plataformas como Airbnb, E-bay e Mercado Livre ${ }^{10}$, para mencionar apenas algumas; enquanto as pequenas e médias empresas são vistas como consumidores devido a vulnerabilidades específicas de certos setores, como telecomunicações e serviços financeiros (BRASIL, 2015).

Por fim, os avanços tecnológicos ainda estão em desenvolvimento, trazendo a "realidade" da Web 3.0 e todos os dados e algoritmos envolvidos, supostamente para facilitar a vida das pessoas, mas às custas da privacidade e dos dados dos consumidores. Publicidade personalizada, produtos, serviços, assistência pessoal (Siri, Alexa and OKGoogle) deveriam implicar que os consumidores sejam informados de todos os riscos e condições de acesso a esses serviços (O'FLAHERTY, 2019; GEBHART, 2018; GOOGLE, s/d).

Não é fácil definir o comércio eletrônico e a economia digital, pois há vários aspectos que precisam ser considerados. O que começou com transações de vendas pela Internet, acessando o site de uma empresa (ou talvez diretamente o fornecedor) (UNCTAD, 2017) divide-se e multiplica-se hoje em uma série de outros relacionamentos, indo além do B2C (Business to Consumer), incluindo vários outros atores.

${ }^{10}$ É importante destacar que existem decisões judiciais na América Latina (Buenos Aires e São Paulo) que consideram a plataforma Mercado Libre como fornecedor, portanto, responsável pelas transações realizadas na sua página. 
Além do Manual da UNCTAD sobre Proteção ao Consumidor, encontramos referências a esse comércio complexo no Relatório de Economia da Informação de 2015 da UNCTAD:

(...) purchases and sales conducted over computer networks, using multiple formats and devices, including the web and electronic data interchange, using personal computers, laptops, tablets and mobile phones of varying levels of sophistication. E-commerce may involve physical goods as well as intangible (digital) products and services that can be delivered digitally (UNCTAD, 2015).

As Diretrizes da OCDE para a Proteção do Consumidor no Contexto do Comércio Eletrônico (1999), atualizadas em 2016, mencionam:

(...) certain special characteristics of electronic commerce, such as the ease and speed with which businesses and consumers can communicate about goods and services and engage in cross-border transactions, may create commercial situations which are unfamiliar to consumers and which may put their interests at risk, it is increasingly important for consumers and businesses to be informed and aware of their rights and obligations in the electronic marketplace [reconhecendo a importância de fornecer um comércio eletrônico aos consumidores onde a] (...) protection that is not less than the level of protection afforded in other forms of commerce (OECD, 2016).

Mesma terminologia é utilizada pelas Diretrizes das Nações Unidas para a Proteção do Consumidor, no ponto III (j) das UNGCP, Princípios Gerais, como uma das necessidades legítimas dos consumidores: “(j) Proporcionar aos consumidores que usam o comércio eletrônico proteção tão eficaz quanto aqueles que usam outras formas de comércio”.

No entanto, nenhum desses documentos ou referências para operadores de proteção ao consumidor define comércio eletrônico; o que ele de fato é, e o que ele envolve. Na verdade, dada a alta velocidade do desenvolvimento tecnológico, pode ser inadequado estabelecer uma definição limitada. O advento da mídia social também está desempenhando um papel relevante no desenvolvimento dessa economia digital. Aqui não estaremos nos referindo apenas às mídias sociais como uma nova ferramenta de comunicação. Na verdade, vai além: as mídias sociais são utilizadas hoje 
como um dos mercados de maior sucesso - plataformas comerciais: Facebook, Instagram e até plataformas de jogos são utilizadas, além de canais de comercialização. Hoje, não se faz apenas compras em websites, mas também em diferentes plataformas e aplicativos, por meio de acessos diferentes.

Portanto, além do e-commerce, temos o "mobile commerce"; comércio disponível por meio do telefone celular, onde se pode instalar e acessar várias outras plataformas e serviços: aplicativos para companhias aéreas, aplicativos para hotéis, aplicativos para compra de produtos, aplicativos para transportes, aplicativos para serviços financeiros, jogos, ginástica, etc. Além disso, a forma como essas plataformas foram criadas e projetadas é comparável à dos jogos: são projetadas de tal forma que os consumidores passam cada vez mais tempo assistindo, conferindo, viciando-se nelas, continuando sujeito a milhares de anúncios e incentivos para continuar consumindo imagens, jogos, ideias, etc.

O principal facilitador desse acesso tem sido os smartphones, que alcançaram diversos mercados ao redor do mundo: vestuário, educação, alimentação e entretenimento, além do setor financeiro. Uma ferramenta, como um smartphone, fornece acesso a bens e serviços em diferentes partes do mundo, de diferentes partes do mundo. A economia digital, portanto, impactou diversos mercados, como o setor financeiro, que estão mudando a vida dos consumidores.

É imenso o impacto na vida das pessoas, dos consumidores, especialmente nas economias em desenvolvimento: nos países em desenvolvimento, o fator de consumo e, principalmente, o acesso a serviços financeiros e a determinados produtos, os eletrônicos, têm um significativo aspecto de inclusão. Precisamente, pelo simples fato de ter acesso a uma conta bancária, a um cartão de crédito ou a um smartphone, o consumidor sente-se inserido, incluído, assim, sentindo-se de fato um cidadão.

Uma vez que esses "novos consumidores" são incluídos, como protegêlos? Além disso, como proteger os consumidores em geral, quando novos 
canais de consumidores surgem, sejam eles sites de comércio eletrônico ou diferentes aplicativos e serviços (eBay, Mercado Libre, Alibaba, Instagram, Facebook, aplicativos financeiros e outros serviços), apresentando desafios para a proteção e desenvolvimento das economias nacionais? Como debater a solução de controvérsias de consumo quando países em desenvolvimento e países desenvolvidos enfrentam os mesmos desafios nos mesmos setores, telecomunicações, serviços financeiros, e-commerce, por exemplo? E o fato de que o comércio está se tornando cada vez mais internacional, sem fronteiras (RIEFA; HUNTER, 2017)?

Podemos acessar livros e músicas de todo o mundo. Os chamados produtos digitais estão disponíveis por meio de vários fornecedores e canais: sites, canais de mídia social e aplicativos. Mas e o pós-venda? Quais são os canais pelos quais os consumidores podem reclamar? Que ferramentas eficazes - existem para proteger os consumidores e fornecer-lhes o direito fundamental de reclamar?

A economia digital e os avanços tecnológicos fornecem aos consumidores publicidade, produtos e serviços sob medida, mas e quanto ao reparo? E quanto à solução de controvérsias? O nível de personalização, acesso e sofisticação dos produtos e serviços, da oferta de produtos e serviços não tem sido o mesmo no que diz respeito ao acesso à informação, ao acesso no pós-venda.

Os esforços para implementar uma estrutura no comércio eletrônico que inclua o acesso à solução de conflitos e reparação, não devem ser vistos como algo especial ou independente, mas são parte dos princípios nos quais se baseiam a proteção do consumidor como a justiça e a informação adequada. O acesso à informação e reparação, boa fé, segurança, privacidade, devem ser considerados como parte intrínseca das relações de consumo, tanto no mundo virtual quanto real, tanto durante a venda quanto no pós-venda. Considerando que esses princípios são universais, como 
garanti-los e aplicá-los? Como garantir o acesso à justiça fornecendo ferramentas para a resolução de conflitos de consumo?

\section{Opções para a solução de conflitos de consumo em um comércio internacional}

Existem diferentes modelos de procedimentos para o tratamento da reclamação de consumidores, que variam de acordo com a estrutura de proteção ao consumidor do país, entre outros fatores. As políticas de proteção ao consumidor e sua aplicação podem variar de país para país: sendo um único órgão responsável pela agenda de proteção do consumidor; ser várias autoridades diferentes compartilhando competência na proteção do consumidor; ou às vezes de grande importância para o trabalho das associações de defesa do consumidor (sociedade civil). As autoridades de defesa do consumidor também podem receber poderes técnicos específicos e especiais relacionados, entre outros, à vigilância do mercado, segurança do produto, qualidade do produto e controle de preços ${ }^{11}$, educação e coordenação de políticas.

Os consumidores prezam as empresas que respeitam seus direitos; produtos que atendem às suas necessidades; e com a mudança da economia digital, os consumidores valorizam procedimentos, informações, respostas e entrega rápidas e eficientes. Quando os consumidores experimentam uma situação negativa na relação de consumo, eles buscam o fornecedor esperando que a solução ou as informações sejam fornecidas de forma rápida, eficiente e conveniente. É por isso que os consumidores geralmente preferem os mecanismos de reparação extrajudicial mais rápidos e eficazes. Após o desenvolvimento das ferramentas digitais, os consumidores tendem a procurar métodos mais práticos, como os oferecidos online.

\footnotetext{
${ }^{11}$ Foi o que ocorreu com vários países em desenvolvimento, como Argentina, Uruguai e Brasil, devido à alta taxa de inflação observada nas décadas de 1970-1980 (LEITÃO, 2011).
} 
Frequentemente, os consumidores não estão cientes das diferenças entre um procedimento de reclamação supervisionado ou coordenado por um especialista em direitos do consumidor e outro que não é monitorado ou coordenado por uma autoridade formal de direitos do consumidor. É, portanto, essencial que as organizações de defesa do consumidor e a sociedade civil (associações) de defesa dos direitos do consumidor participem desse processo para esclarecer direitos, minimizando vulnerabilidades e riscos. Nos últimos dez anos, testemunhamos uma série de iniciativas e esforços no sentido de prover acesso a solução de conflitos de consumo, provendo uma atenção especial ao consumidor internacional, ao turista, ao consumidor transfronteiriço.

Uma iniciativa que merece destaque é a da Conferência Interamericana de Direito Internacional Privado no âmbito da Assembleia Geral da Organização dos Estados Americanos (OEA). A ideia inicialmente proposta por Brasil, Argentina e Paraguai foi a de elaborar uma Convenção Interamericana sobre a Lei Aplicável a Certos Contratos e Transações Internacionais de Consumo (OEA, 2008). A chamada "Proposta de Buenos Aires" visava

(...) to establish a legal regime in the matter of applicable law that affords more favourable and special protection to consumer in their international contracts and transactions with professionals and providers of goods and services, whether as tourists or distance sales, thereby making it possible to expand the circulation of goods and services as well as consumers options, without discrimination, in the regional market (OEA, 2008).

Infelizmente, a proposta não teve sucesso sem o apoio dos EUA. Tais ideias de cooperação internacional não foram, no entanto, totalmente ignoradas, o que mais tarde levou à criação da Rede de Segurança e Saúde do Consumidor (RSSC) ${ }^{12}$ (um sistema semelhante ao European Safety

12 Cf. as propostas do working group da OEA em proteção do consumidor em: http://www.oas.org/fr/sla/rssc/default.asp. 


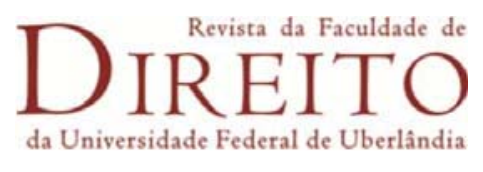

Gate $^{13}$, o antigo Rapex, um sistema de alerta de recall de produto). O mesmo objetivo estava dentro da "Proposta de Buenos Aires", um acordo de cooperação internacional que oferece aos consumidores acesso à justiça e resolução de controvérsias em dois outros órgãos distintos: os países da América do Norte, Sul no MERCOSUL e a Conferência de Haia Direito Internacional Privado (HCCH).

No âmbito do MERCOSUL, a cooperação entre os órgãos de defesa do consumidor dos Estados membros tem sido positiva desde o início, apoiando a ideia de um acordo formal no âmbito do bloco (LIMA MARQUES, 2019). Os esforços bem-sucedidos e a cooperação foram documentados e se tornaram um estudo de caso para a proposta apresentada no nível da HCCH. No final de 2017, a proposta de cooperação foi finalmente aprovada no âmbito do Conselho do Mercado Comum (CMC), a maior autoridade regional de mercado do MERCOSUL.

O "Acuerdo del MERCOSUR sobre derecho aplicable en materia de contratos internacionales de consumo", além de constituir uma etapa histórica para a proteção internacional dos consumidores, também cria um precedente muito interessante e relevante no que diz respeito à competência no campo da proteção ao consumidor: no artigo 4, o Acordo do Mercosul estabelece que:

Artigo 4.1 - Os contratos internacionais celebrados quando o consumidor se encontra no Estado Parte do seu domicílio, nomeadamente no caso de um contrato à distância, regem-se pela lei escolhida pelas partes, que podem escolher a lei do domicílio do consumidor, do lugar da celebração ou a execução do contrato ou a sede do fornecedor dos produtos ou serviços. A lei escolhida será aplicável sempre que for mais vantajosa para o consumidor. (MERCOSUL, 2017 - tradução livre).

E ainda:

Artigo 5 - Contratos celebrados pelo consumidor fora do Estado parte de seu domicílio 1 - Os contratos internacionais de consumo, celebrados pelo consumidor fora do Estado parte do seu domicílio,

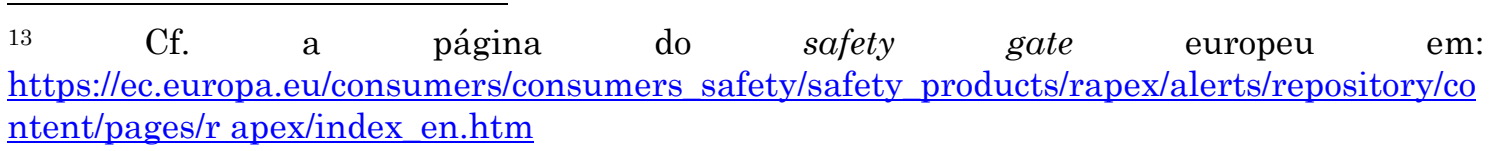


regem-se pela lei escolhida pelas partes, que podem validamente escolher a lei do lugar da celebração ou execução do contrato ou do domicílio do consumidor. A lei escolhida será aplicável sempre que for mais vantajosa para o consumidor (MERCOSUL, 2017 tradução livre).

Reconhecer as vulnerabilidades dos consumidores internacionalmente, no comércio internacional, oferecendo-lhes não só a possibilidade de escolher a lei aplicável, mas também a lei mais favorável (como consumidor) abre um caminho importante. Além disso, o Acordo MERCOSUL refere-se - e é aplicável - ao comércio off-line e on-line, sendo, portanto, aplicável ao comércio eletrônico internacional (nos Estados Membros do MERCOSUL).

Conforme mencionado, a iniciativa do MERCOSUL também abriu caminho para a proposta de fundamentação semelhante à Conferência de Haia de Direito Internacional Privado $(\mathrm{HCCH})$ para criar uma convenção para a solução de controvérsias de consumo, ambas propostas, preconizadas pela Professora Claudia Lima Marques (2013). A proposta de convenção sobre cooperação e acesso à justiça para turistas internacionais foi apresentada pela primeira vez pelo Brasil, com o apoio de todos os países latino-americanos, além de outros membros da $\mathrm{HCCH}$, como a China ${ }^{14}$.

A proposta foi inicialmente mal recebida e considerada um assunto regional (MERCOSUL). No entanto, China e Rússia demonstraram interesse em permitir que a proposta fosse incluída na agenda da Conferência da Haia. Este mesmo fato é histórico: pela primeira vez na história da $\mathrm{HCCH}$ (120 anos na época), uma proposta de um país em desenvolvimento foi aceita para discussão e oficialmente listada na agenda de projetos da Conferência (KLEIN VIEIRA; CARDOSO SQUEFF, 2020).

A proposta de Convenção na $\mathrm{HCCH}$ sobre cooperação e acesso à justiça para turistas internacionais é uma iniciativa internacional que visa proporcionar aos consumidores (enquanto turistas) um acesso efetivo à

14 Cf. a proposta e demais documentos relacionados ao tema em: https://www.hcch.net/en/projects/legislative-projects/protection-of-tourists 
justiça por meio da cooperação das agências de proteção ao consumidor e do sistema judicial dos Estados Membros. Isso significa que a proposta do $\mathrm{HCCH}$ representa uma ação efetiva no campo da cooperação internacional, conforme preconizam as Diretrizes das Nações Unidas de Proteção ao Consumidor (Princípio 89). ${ }^{15}$

Esses exemplos demonstram a crescente importância da proteção internacional do consumidor e a inevitabilidade do desenvolvimento de novas plataformas para a resolução rápida, acessível e eficiente de conflitos de consumo. Com relação às Américas, a América do Sul tem liderado a melhoria da cooperação para melhor proteger os consumidores da região. Ao mesmo tempo, a Europa tem seu próprio sistema de solução de conflitos online (mencionado abaixo) e os países da ASEAN estão em vias de desenvolver sua própria plataforma. Na evolução da Economia Digital, produtos e serviços são criados e desenvolvidos conforme surgem e são criadas novas necessidades: o acesso à informação e meio de solução de conflitos devem ser igualmente facilitados para o consumidor.

\section{A participação do Estado na criação de novas plataformas para a solução de conflitos}

As Diretrizes das Nações Unidas para a Proteção do Consumidor mencionam especificamente a resolução de disputas de consumo e procedimentos de reparação na Seção F, Resolução de Litígios e Recurso, N. 37-41, que convida, os Estados Membros, a criarem mecanismos de reparação que devem ser facilitados, acessíveis, levando em consideração as vulnerabilidades de, por exemplo, consumidores de baixa renda.

Juntamente com o acesso à informação, a resolução de litígios e o direito à reparação, são direitos fundamentais do consumidor. Talvez o

15 "Os Estados-Membros devem considerar a participação em mecanismos multilaterais e bilaterais a fim de fortalecer a cooperação judiciária e entre agências com o objetivo de recuperar ativos estrangeiros e fazer cumprir as decisões em litígios transfronteiriços" (NACIONES UNIDAS, 2015, Princípio n. 89). 
assunto, que no passado dizia respeito apenas à competência das autoridades de consumidores e de algumas associações de consumidores, tenha aumentado em importância e diversidade na última década. Com as novas formas de comércio, o acesso a produtos e serviços e, claro, o advento da economia digital, surges novas formas, métodos e acesso à resolução de litígios e reparação.

O direito do consumidor à reparação é consequência de uma violação de contrato, de uma prática desleal ou, por vezes, de um prejuízo, como no caso da saúde e segurança do consumidor. Portanto, garantir a reparação para os consumidores, permitindo-lhes acesso à informação e a canais de reclamação, constitui um direito fundamental dos consumidores: "Quanto mais o mundo caminha para as relações econômicas baseadas nas transações, mais os sistemas de resolução de conflitos se tornam necessários. Isso se deve em parte ao grande volume de transações (...)" (UNCTAD, 2017).

Alguns modelos interessantes desenvolvidos recentemente fornecem aos consumidores melhor acesso à informação, resolução de disputas e reparação. Existem diferentes tipos de procedimentos para resolver disputas de consumo, como arbitragem, mediação e negociação. O vocabulário pode variar e possuir diferentes significados de um país para outro, de uma legislação para outra. Portanto, é importante esclarecer e explicar que, no que se refere aos direitos do consumidor, qualquer tipo de ferramenta pode ser válido, desde que existam normas específicas escritas e aprovadas (pelas autoridades de defesa do consumidor) a saber: o reconhecimento do vulnerabilidades de justificar de fato a proteção dos consumidores - as vulnerabilidades dos consumidores aos fornecedores ${ }^{16}$.

Os procedimentos de solução alternativa de conflitos, estão crescendo em popularidade na era da economia digital e no desenvolvimento da resolução de disputas online. Existem alguns exemplos de ferramentas de

16 Vulnerabilidades do consumidor: informativa, econômica, jurídica e técnica. 
sucesso: a resolução de litígios online da União Europeia, a plataforma brasileira consumidor.gov e a mexicana Concilianet. De acordo com as Diretrizes das Nações Unidas para a Proteção do Consumidor (NACIONES UNIDAS, 2015) o acesso à solução de litígios e mecanismos de reparação, incluindo mecanismos alternativos de resolução de litígios, devem ser aperfeiçoados, em particular em litígios transfronteiriços. Isso é particularmente relevante para o comércio eletrônico: um consumidor que adquire um bem ou serviço online espera poder resolver disputas com a empresa/fornecedor por meio da mesma plataforma.

A Resolução de Disputas de Consumo Online consiste em mecanismos de solução de disputas facilitados pelo uso de comunicações eletrônicas e outras tecnologias de informação e comunicação e está em ascensão como meio de fortalecer a confiança do consumidor no comércio eletrônico, especialmente no exterior (NACIONES UNIDAS, 2015, sec. 1). Os sistemas de Resolução de Disputas de Consumo Online foram desenvolvidos inicialmente por plataformas de fornecedores, como eBay e PayPal, com o objetivo de aumentar o nível de satisfação do consumidor em seus mercados.

Essas plataformas lidam atualmente com mais de 60 milhões de casos por ano, em comparação com menos de 300.000 no sistema judicial dos Estados Unidos (RULE, 2012). Outras empresas como Modria, Resolver, SmartSettleOne, VirtualCourtHouse e Youstice, surgiram recentemente. Há uma preocupação crescente com a supervisão de transações privadas de solução de conflito de consumo online, uma vez que os consumidores podem ser mais facilmente enganados sobre seus direitos processuais e substantivos, o que aumentou a supervisão pública nos últimos anos.

Os procedimentos por parte das autoridades de defesa do consumidor continuam a carecer em publicidade, para que mais consumidores possam ser informados dos seus direitos e da possibilidade de utilizarem outros instrumentos de resolução de litígios. Muitos são os exemplos de ações nesse sentido, como podemos ver nas linhas a seguir. 


\subsection{Modelo Europeu}

A plataforma de solução de litígios online da União Europeia (ODR platform), desenvolvida pela Comissão Europeia tem por objetivo ajudar consumidores e comerciantes a resolver suas disputas contratuais relacionadas à compra online de bens e serviços de curto prazo e baixo custo, de forma simples e rápida. O sistema permite que os consumidores enviem suas disputas online em qualquer uma das 23 línguas oficiais da União Europeia. A plataforma de resolução de litígios online apenas retransmite os litígios a organismos de resolução de litígios indicados pelos EstadosMembros.

Semelhante ao projeto MERCOSUL e à proposta na Conferência da Haia, os Estados Membros estabelecem um ponto de contato nacional para prestar assistência aos usuários da plataforma de resolução de disputas online que está em operação desde fevereiro de 2016. De acordo com a Diretiva de Solução de Controvérsias de Consumo (UNIÃO EUROPEIA, 2013), todas as empresas estabelecidas na UE que vendem bens ou prestam serviços aos consumidores online devem cumprir a legislação sobre a solução de conflitos de consumo online.

\subsection{Modelo Português}

Um exemplo interessante é o português "Livro de Reclamações" (PORTUGAL, s/d). De acordo com o Decreto Legislativo no 156/2005, é dever das empresas fornecer aos consumidores o livro de reclamações em cada estabelecimento comercial. O livro tem páginas numeradas (contendo até 25 reclamações) e cada reclamação registrada possui três vias: uma para ficar no livro (em amarelo), uma para o consumidor (em azul) e outra para 
encaminhá-las às autoridades (vermelho) dentro de 15 dias. Neste caso, a Direção-Geral do Consumidor de Portugal é o ente público, integrado no Ministério da Economia, responsável por contribuir para o desenvolvimento, definição e implementação da política de defesa do consumidor em Portugal, bem como como a coordenação e gestão do livro de reclamações

Este registo de reclamações, portanto, não é apenas um instrumento de fiscalização, mas também confere aos consumidores transparência, informação e o direito de reclamar de uma empresa, produto ou serviço. Desde $1^{\text {o }}$ de julho de 2018, o livro de reclamações também está disponível online ${ }^{17}$. A nova versão online do livro é, de fato, um programa e envolve a Direção Geral do Consumidor, a Agência de Defesa do Consumidor de Portugal e reguladores de diversos setores. O cadastro eletrônico de reclamações é direcionado a todos os consumidores, inclusive estrangeiros, e a plataforma também possui uma versão em inglês.

As empresas agora são obrigadas a ter as duas versões do livro de reclamações: no local e online. De acordo com o Decreto Lei n. 74/2017, as empresas também devem informar os consumidores sobre o novo acesso online ao Livro de Reclamações e divulgá-lo em seus sites de forma acessível e independente de outros mecanismos de reclamação. As penas por incumprimento da lei podem variar entre 150 e 15.000 euros.

\subsection{Modelo Mexicano}

Fornecido e coordenado pela PROFECO (Procuraduria Federal del Consumidor, Advogada-Geral do Consumidor) a Concilianet e é uma plataforma de solução online de litígios que disponibiliza mediação via Internet mediante apresentação de um representante da PROFECO, um representante da empresa e do consumidor.

\footnotetext{
${ }^{17}$ Cf. o site em https://www.livroreclamacoes.pt/inicio
} 
A iniciativa oferece aos consumidores a possibilidade de resolver suas disputas em casa, acessando a plataforma de autoridade do consumidor. Todo o procedimento é feito via Internet, todos os documentos e cadastros são feitos online, via plataforma. Todas as imagens de documentação necessárias ou relevantes, comprovantes de pagamento, podem ser inseridos ou enviados online. No prazo de dez dias úteis, a autoridade do consumidor dá resposta à reclamação, declarando-se competente para a receber, indeferindo ou solicitando informações adicionais.

Uma vez que a reclamação é aceita, a autoridade fixa uma data para a mediação online. No final do procedimento de mediação, o consumidor receberá um questionário sobre o serviço prestado pela Concilianet. De acordo com o relatório anual da Profeco (MÉXICO, 2018), em 2018, Concilianet atendeu 6.790 casos, com um percentual de $86,50 \%$ de casos resolvidos.

\subsection{Modelo Colombiano}

A Superintendência do Comércio e Indústria colombiana (SIC) também possui seu próprio sistema online de resolução de disputas de consumo, no qual a SIC atua como um "facilitador" para que consumidores e fornecedores possam chegar a um acordo. SIC-Facilita disponibiliza a empresas e consumidores uma plataforma (chat) onde fornecedores e consumidores, com a ajuda da SIC, podem chegar a acordo sobre litígios decorrentes de garantias, ofertas de produtos ou serviços, publicidade enganosa, evitando medidas judiciais.

O objetivo da iniciativa é desenvolver a cultura de prestação de serviço pós-venda entre os fornecedores (nomeadamente dando aos consumidores acesso a informações e reclamações); oferecer a empresas e consumidores mais uma alternativa de resolução de conflitos, evitando o 
descontentamento do consumidor e demandas adicionais ao Judiciário. Segundo dados da SIC, até $70 \%$ das reclamações encaminhadas são resolvidas por meio da mediação online.

\subsection{Modelo Brasileiro}

A criação da plataforma brasileira é baseada no disposto no artigo $4^{\circ}$, inciso V, da Lei Federal n. 8.078/1990 (Código de Defesa do Consumidor) e no artigo $7^{\circ}$, incisos I, II e III, do Decreto n. 7.963/2013. Como resultado de uma série de iniciativas relacionadas à melhoria da economia brasileira e ao acesso, pela primeira vez, de milhões de consumidores a diversos produtos e serviços (acesso a eletrônicos, serviços financeiros e seguro saúde, para citar apenas os principais), as autoridades brasileiras elaboraram um plano nacional (PLANDEC, aprovado via Decreto n. 7.963/2013) para prover acesso à justiça.

O Brasil tem mais de 5.000 cidades, sendo que nem todas possuem uma autoridade de defesa do consumidor. O consumidor.gov.br foi desenvolvido e criado para preencher essa lacuna e oferecer aos consumidores uma nova ferramenta de solução de conflitos. É um serviço público que permite o diálogo direto entre consumidores e empresas para a resolução de conflitos de consumo por meio da plataforma consumidor.gov. Um dos principais fatores que explicam o sucesso dessa iniciativa está no fato de ser baseada na cooperação entre a autoridade nacional, a Secretaria Nacional do Consumidor - Senacon - do Ministério da Justiça e Segurança Pública e as empresas participantes, por meio da assinatura de um termo de cooperação com a Senacon.

Outro fator que explica a eficácia da plataforma é a possibilidade de o órgão federal, Senacon, assim como autarquias (conhecidas como Procons, órgãos locais de defesa do consumidor), promotores, procuradores e 
sociedade, poderem acompanhar o sistema que é atualizado em tempo real contendo informações como: os setores mais reclamados, as empresas mais reclamadas, a rapidez das empresas em responder demandas, o nível de satisfação dos consumidores, entre outros, criando uma competição natural e saudável entre as empresas no tratamento de reclamações.

Assim, a plataforma possibilita a solução de conflitos de consumo com agilidade evitando burocracias. Segundo dados da Senacon, atualmente 80\% das reclamações registradas no Consumidor.gov.br são resolvidas por empresas que respondem às consultas dos consumidores em um prazo médio de 7 dias.

A transparência nos dados disponibilizados na plataforma tem-se revelado positiva não só no que diz respeito à informação, mas também à informação pública que as autoridades são obrigadas a partilhar e que se espera que as empresas prestem, mas também ao sistema e ao mercado. Diferentemente das iniciativas do México e da Colômbia, o modelo brasileiro não exige nenhuma mediação online "ao vivo" por meio de "chat" ou videoconferência. $\mathrm{O}$ consumidor entra em contato com a empresa por meio da plataforma consumidor.gov (.br), fornecendo-lhe toda a documentação e todas as informações relativas ao caso.

A empresa deve reagir em 10 dias, caso contrário, pode ser demandada pela autoridade do consumidor que está acompanhando o processo online. Além disso, caso a solicitação não for resolvida ou o fornecedor não cumprir o que foi acordado diretamente com o consumidor por meio do Consumidor.gov, o consumidor pode utilizar o histórico da solicitação feita na plataforma e executar diretamente perante a autoridade do consumidor (seja local, municipal; ou regional, estadual).

Dada a eficiência da plataforma e o fato de mais de $70 \%$ das ações judiciais (pequenas causas) serem relacionadas ao consumidor, foi recentemente assinado um acordo entre a autoridade federal, a Senacon, e o Conselho Nacional de Justiça (CNJ) pela integração da plataforma 
Consumidor.gov.br ao processo judicial eletrônico (PJe) (AASP, s/d). A parceria deve tornar ainda mais eficaz na resolução de disputas de consumo.

Conforme observado acima, os exemplos de iniciativas mencionados são todos implementados e/ou controlados pelo estado. De fato, as ADR, no que se refere aos direitos do consumidor, são eficazes quando coordenadas, apoiadas e monitoradas por órgãos de defesa do consumidor ou organizações da sociedade civil. Qualquer outro tipo de solução de conflito de consumo que não envolva uma autoridade de defesa do consumidor ou representante da sociedade civil pode resultar na redução dos direitos do consumidor em qualquer tipo de negociação.

De acordo com a Consumers International, 56\% das organizações de consumidores membros em todo o mundo afirmam que os provedores de serviços digitais não oferecem sistemas de autoatendimento em seus países e que não há obrigação legal de fazê-lo (CI, 2017). Considerando o incremento da Economia Digital, particularmente impulsionada pelas medidas sanitárias durante a crise da pandemia causada pela Covid-19 (em especial entre 2020 e 2021), não resta dúvida de que tais regras devem ser atualizadas à uma realidade que se exige acesso à distância, aos mais diversos produtos, serviços e claro soluções.

Os consumidores de hoje, consumidores da era digital, exigem não apenas acesso rápido e transparente a produtos e serviços, mas também a negócios, informações e resolução de disputas. É possível criar plataformas de resolução de conflitos de consumo sem a participação do Estado? Qual é o futuro da solução de conflito de consumo online e da participação do estado neste processo?

\subsection{A participação do Estado}

O direito do consumidor, assim como o direito do trabalho, são os dois exemplos clássicos de sistemas jurídicos que inevitavelmente desafiam 
novas formas de resolução de conflitos. É importante esclarecer a defesa do consumidor com base na legislação, no direito do consumidor (na maioria dos países), um fato que não pode ser ignorado, enquanto novas formas de resolução de disputas podem ser necessárias. Resultado de formas de resolução de conflitos que não são necessariamente definidas por lei, como a autorregulação, por exemplo.

A questão é que, em caso de litígio de consumo, o direito do consumidor não pode ser ignorado. A situação de vulnerabilidade do consumidor requer uma proteção especial, para garantir um relacionamento mais equilibrado. Hoje, estamos testemunhando uma transformação do sistema que está sofrendo o impacto da economia digital: os consumidores estão cada vez mais exigentes. As novas gerações de consumidores estão acostumadas a transações rápidas: a compra de produtos e serviços; pagar contas com um clique e em caso de problema, em caso de falha de produto ou serviço, o consumidor também espera soluções rápidas e eficientes; o que geralmente não é o caso. Para responder a essas novas demandas, governos e outros atores (como organizações regionais da ASEAN, MERCOSUL, UE ou mesmo UNCTAD) têm trabalhado para formar parcerias destinadas a criar novas plataformas para a resolução de disputas.

Como visto nas páginas anteriores, a proteção do consumidor se refere à proteção de uma parte mais fraca em uma relação de consumo desequilibrada e, portanto, a ausência do Estado não pode ser aceita. Com o advento da economia digital, as relações de consumo na esfera digital podem colocar os consumidores em uma posição ainda mais vulnerável e desfavorecida: o aspecto internacional também deve ser levado em conta quando percebemos que grande parte do consumo online é, de fato, consumo internacional.

Como menciona Schultz (2011), existem muitos desafios para resolver disputas no ciberespaço devido à distância física entre as partes. $\mathrm{O}$ fato de as transações serem pequenas ou médias e de pedir ressarcimento 
pode acarretar custos que excedem o valor do produto-serviço e, por fim, o tema eficiência, engajamento das partes, cumprimento da lei. Os exemplos acima mencionados, nomeadamente os de Portugal, México e Brasil, mostram que, no caso da solução de conflito de consumo online, a participação do Estado, a presença do Estado para conferir este efeito vinculativo, é fundamental.

Além disso, o exemplo do consumidor.gov (brasileiro) mostra que a cooperação Estado - Empresa - Consumidor é possível e pode ser frutífera. Nesse caso, o sistema sendo construído e baseado em um acordo de cooperação - convênio firmado - entre as empresas e o Estado, confere transparência e eficiência, vinculando as partes interessadas (SHULTZ, 2011). O caso especial de litígios internacionais de consumo a vulnerabilidade do consumidor, o desequilíbrio de poder em litígios na Internet alegado por Hörnle refere-se especificamente às vulnerabilidades dos consumidores. Como amplamente argumentado na convenção proposta apresentada à Conferência da Haia de Direito Internacional Privado $(\mathrm{HCCH})$, os consumidores internacionais são ainda mais vulneráveis e desfavorecidos por uma série de fatores como diferenças culturais, idioma, ambiente diferente (turismo) ou precisamente por conta das próprias especificidades do mundo virtual.

Klein Vieira (2017), classifica uma nova categoria de consumidores, o "consumidor transfronteiriço", como ainda mais vulnerável à aquisição de bens e serviços fora do seu território nacional. Em sua tese de doutorado, Klein Vieira (2017) também argumentou que não é possível garantir a resolução de conflitos de consumo sem a presença do Estado. Além disso, se considerarmos que as vulnerabilidades dos consumidores vis-à-vis as empresas (vulnerabilidade financeira, vulnerabilidade jurídica, vulnerabilidade técnica) são reforçadas a nível internacional, não é possível nem aceitável imaginar a resolução de litígios de consumo online sem algum tipo de envolvimento do Estado. 
Conforme igualmente defendido por Hörnle e Schultz, litígios e arbitragem desempenham uma função pública. O mesmo pode ser dito sobre o que é chamado de resolução de disputas de consumo online. No entanto, neste caso, a presença do Estado tem uma consequência crucial para a eficiência.

Dadas as vulnerabilidades do consumidor já mencionadas, as peculiaridades do direito do consumidor, as dificuldades de resolução de litígios online, colocando os consumidores - mais uma vez - em posição de vulnerabilidade, ainda não é possível pensar na resolução de litígios de consumo, métodos alternativos de resolução de litígios bem-sucedidos e plataformas sem a participação, presença ou fiscalização do Estado.

Aqui o modelo mais interessante e de sucesso é o do Brasil, consumidor.gov que foi desenvolvido em colaboração com empresas, criando uma concorrência saudável entre as empresas, produzindo resultados positivos. Além disso, a fiscalização Estatal (realizada tanto pela autoridade federal quanto pelas autoridades locais e regionais de defesa do consumidor) on-line e formalmente vinculada por um acordo de cooperação firmado entre as empresas e a autoridade Federal de Defesa do Consumidor, SENACON, fornece suporte jurídico para a iniciativa.

É possível, portanto, criar plataformas de resolução de conflitos de consumo sem a participação do Estado? Não, no caso da defesa do consumidor, pelas vulnerabilidades dos consumidores que se agravam internacionalmente e são intensificadas no meio virtual, é impossível criar plataformas eficazes de resolução de conflitos de consumo sem a participação do Estado. Portanto, o envolvimento do Estado na criação, desenvolvimento e monitoramento (ao menos), de uma plataforma de resolução de disputas online para consumidores, é necessário e relevante para que a parte mais fraca, o consumidor, seja devidamente protegida, de forma que as vulnerabilidades dos consumidores frente os fornecedores, sejam, protegidas. 
Em relação ao futuro dessas plataformas e iniciativas, é relevante observar iniciativas recentes como a cooperação de países asiáticos (Regional Comprehensive Economic Partnership - RCEP) ${ }^{18}$, a $11^{\mathrm{a}}$ Cúpula do BRICS organizada no Brasil entre os dias 13-14 de novembro de 2019 e a parceria UNCTAD - China Silk Road Group (SOO, 2019).

\section{Perspectivas para o futuro em um cenário de pandemia e crise mundial}

Estamos a assistir a uma nova fase na relação de consumo, resultante da economia digital que tem conduzido à criação de novos produtos e serviços, a novos modos de consumo. A crise resultado da pandemia causada pela COVID-19 obrigou fornecedores e consumidores a se adaptarem à uma nova realidade: as restrições sanitárias ao redor do mundo continuam a impactar economias; diversos setores enfrentam perdas e são obrigados a migrar para plataformas digitais para continuar a venda de produtos e serviços. Muitos consumidores que foram dispensados de seus trabalhos também se voltaram ao empreendedorismo, aprendendo a explorar plataformas e aplicativos da Economia Digital para criar ou aumentar a fonte de renda (OECD, 2021).

Em 2019, a Assembleia Geral das Nações Unidas declarou 2021, como Ano Internacional da Economia Criativa para a Sustentabilidade. Hoje, temos o registro de que o setor da economia criativa, que envolve a cultura e o turismo, foi um dos, senão o mais afetado pela crise causada pela COVID19. Todos fomos obrigados a nos adaptar a uma nova realidade que impulsionou o comércio online de atividades antes limitadas ao presencial: cursos, concertos, exposições, cinema (NETFLIX..., 2020).

Foram diversas as adaptações e imensa a migração para plataformas online. Com esses novos modos de consumo, novos canais e novos serviços,

18 São os países que compõe: China, Japão, Coreia do Sul, Austrália e Nova Zelândia, bem como os dez países da ASEAN: Indonésia, Tailândia, Cingapura, Malásia, Filipinas, Vietnã, Mianmar, Camboja, Laos e Brunei. Cf. mais informações sobre a RCEP em LIY, 2019. 
surge a necessidade de uma resolução mais rápida e eficiente das disputas de consumo. Estes requisitos não estão dissociados do direito do consumidor, pelo contrário, complementam os princípios básicos existentes em termos de defesa do consumidor, acompanhando a evolução do mercado: o acesso rápido e facilitado a produtos e serviços exige uma resolução rápida dos litígios de consumo (CALLIESS, 2006).

A relevância da proteção do consumidor em nível internacional pode ser identificada como resultado de dois grandes desenvolvimentos: a globalização e o advento da economia digital. A globalização, acompanhada pelo desenvolvimento da economia em várias regiões (América Latina, Ásia e, mais recentemente, o continente africano) e o aumento do transporte internacional de pessoas e trabalhadores; e a economia digital, que oferece cada vez mais acesso a bens e serviços que, há 20 anos, só eram acessíveis a um determinado número de pessoas.

Podemos citar alguns exemplos de ações que visam a implantação de um sistema internacional de proteção ao consumidor e que comprovam o desenvolvimento da proteção ao consumidor no âmbito internacional:

1. No âmbito OEA, que liderou à criação da Rede de Saúde e Segurança para as Américas no European Rapex, um sistema de alerta de recall de produtos;

2. o projeto de convenção sobre a proteção dos turistas (consumidores como turistas) na $\mathrm{HCCH}$, que incide sobre a criação de uma rede de autoridades de proteção do consumidor (tanto a nível administrativo como judicial) para resolver o consumidor internacional disputas, e mais recentemente (2015)

3. a revisão das Diretrizes das Nações Unidas para a Proteção do Consumidor $^{19}$, (2015) que levou a confiar à UNCTAD o mandato de Direito e

\footnotetext{
${ }^{19}$ A segunda e última reforma do UNGCP revisou e aprovou um documento internacional em tempo recorde, em menos de cinco anos, não só introduzindo temas relevantes como proteção de dados e privacidade e ecommerce, mas também reconhecendo a importância da
} 
Política do Consumidor (UNGCP), bem como à criação de um grupo intergovernamental de especialistas na área de proteção e política do consumidor (IGE-Consumer).

Hoje, com o advento de novas plataformas e canais para resolver disputas de consumo, como a plataforma europeia de resolução de disputas online, a mexicana Conciliianet, a colombiana Sicfacilita ou a brasileira consumidor.gov(.br), outras partes do mundo se concentram no desenvolvimento de ferramentas que irão facilitar a resolução de litígios de consumo: os países membros da ASEAN têm trabalhado no desenvolvimento de plataformas na área da proteção do consumidor, como uma plataforma para recalls e outra para resolução de litígios. A recente cooperação de países asiáticos através da RCEP, que contempla um capítulo dedicado ao desenvolvimento da defesa do consumidor na região, também atesta o fato de que a proteção ao consumidor está em constante desenvolvimento em diversas regiões do mundo.

Para completar esta informação, o acordo de cooperação recentemente celebrado entre a UNCTAD e o China Silk Road Group permitirá que os consumidores do Sudeste Asiático resolvam suas disputas online, contribuindo tanto para o comércio internacional quanto para a confiança do consumidor no mercado, impactando positivamente na economia. O projeto visa ajudar o consumidor a aproveitar o relacionamento comercial mais próximo na economia digital, tornando-se um grande exemplo de cooperação internacional na implementação das Diretrizes das Nações Unidas para a Proteção do Consumidor. A primeira metade do projeto trabalhará com dois países beneficiários da região do Sul da Ásia em uma experiência única no desenvolvimento de solução para disputas de consumo online utilizando tecnologias tais como o blockchain. para cooperação, assistência técnica e capacitação no domínio da defesa do consumidor. 


\section{Conclusão}

No comércio, é difícil encontrar um mecanismo mais adequado ou mais equilibrado, sem regras, para orientar as relações comerciais. No caso das relações consumidor-empresa, onde um fator de vulnerabilidade desempenha um papel importante, dificilmente encontraremos um mercado mais "maduro" onde a participação - ou pelo menos a fiscalização - do Estado não seja necessária.

Discutir a maturidade dos mercados e culturas para vislumbrar as relações de consumo sem o poder de controle do Estado levaria a abordagens mais filosóficas. Embora estejamos em um mundo globalizado, ainda não é apropriado comparar nações. Se tentarmos comparar países como Brasil, Alemanha e Suíça, todos os três sistemas federais baseados em legislação escrita com indústrias significativas, as diferenças abissais surgirão no que se refere à história - e, portanto, à cultura - ao número de habitantes; e, claro, o tamanho. É difícil, por exemplo, considerar que a Suíça tenha uma cultura mais madura para estabelecer um sistema de solução de conflitos de consumo sem ao menos a supervisão do Estado e das autoridades. Não é uma questão de cultura, de ser mais ou menos desenvolvido, é a lógica da relação de consumo, com dois atores distintos, fornecedores e consumidores, que exige a fiscalização de uma autoridade responsável pela fiscalização das ações e dos resultados de tais atos para o benefício da economia.

Os Estados podem ajudar a corrigir falhas de mercado, criar uma estrutura legal, regulatória e institucional e fornecer incentivos apropriados para que os participantes do mercado contribuam de forma mais eficaz para o desenvolvimento sustentável. No entanto, a participação e cooperação empresarial é essencial para o sucesso das políticas de defesa do consumidor. As plataformas de resolução de disputas online oferecem uma oportunidade para que as empresas demonstrem seu compromisso com seus 


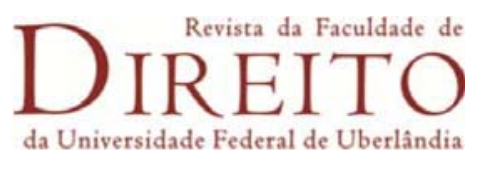

consumidores, dando-lhes acesso à resolução de disputas e resolvendo disputas de consumo.

No entanto, tal opção não pode ser aceita ou não deve ser plenamente frutífera ou efetiva sem a participação do Estado, sem fiscalização do Estado, para que a proteção do consumidor seja plenamente garantida, de forma que os consumidores sejam menos prejudicados por sua maior vulnerabilidade no âmbito internacional.

\section{Referências}

AASP. Plataforma Consumidor.gov.br integra o PJe para soluções online dos conflitos de consumo. s/d. Disponível em: https://www.aasp.org.br/noticias/plataformaconsumidor-gov-br-integra-o-pje-para-solucoes-online-dosconflitos-de-consumo/ Acesso em 21 jan. 2021.

ASEAN. The ASEAN strategic Action Plkan for Consumer Protection 2016-2015. Jacarta: ASEAN, 2016. Disponível em: https://aseanconsumer.org/file/pdf_file/ASAPCP\%20(UPLOADING)\%20-

\%2011Nov16\%20Final.pdf. Acesso em: 21 jan. 2021.

BAUMAN, Z. Consuming Life. Polity Press, London, 2007.

BENJAMIN, Antonio Herman; LIMA MATRQUES, Claudia; BESSA, Leonardo R. Manual de direito do consumidor. 5. ed. Ver. Atual. E ampl. São Paulo: RT, 2013

BRASIL. Lei Federal n. 9.307 de 23 de setembro de 199: Dispõe sobre a Arbitragem. Disponível em: www.planalto.gov.br/ccivil_03/leis/19307.htm. Acesso em: 10 ago. 2021.

BRASIL. Ministério da Justiça/SENACON. Nota Técnica $\mathbf{n}^{\circ}$ 14/2015/assessoria senacon/gab senacon/senacon. Brasília, 26 jun. 2015. Disponível em: https://www.defesadoconsumidor.gov.br/images/manuais/notas_tecnicas/nota-tecnica_14-

2015_mei.pdf. Acesso em: 10 ago. 2021

CALISSES, Gralf-Peter Calliess. Transnational Consumer Law: Co-Regulation of B2C-ECommerce. IN: DILLING, Olaf, HERBERG, Martin, WINTER, Gerd (eds.). Responsible Business: Self-governance in transitional economic transactions. London: Hart 2006.

CASTELLS, M. A Sociedade em Rede, Era da Informação: Economia, Sociedade e Cultura, Volume I, $8^{a}$ Edição, Editora Paz e Terra, São Paulo, 2005

CI - CONSUMERS INTERNATIONAL. About us. s/d. Disponível em: https://www.consumersinternational.org/who-weare/about-us . Acesso em: 21 jan. 2021

CI - CONSUMERS INTERNATIONAL. World Consumer Rights Day Briefing: Redress, Building a Digital World Consumers Can Trust. 2017. Disponível em: https://www.consumersinternational.org . Acesso em: 21 jan. 2021

CR - CONSUMER REPORTS. How We Work for Marketplace Change. s/d. Disponível em: https://advocacy.consumerreports.org . Acesso em: 21 jan. 2021

EUA. Special Message to Congress on Protecting Consumer Interest. Washington D.C., 15 mar. 1962. Disponível em: https://www.jfklibrary.org/AssetViewer/Archives/JFKPOF-037-028.aspx . Acesso em: 21 jan. 2021. 


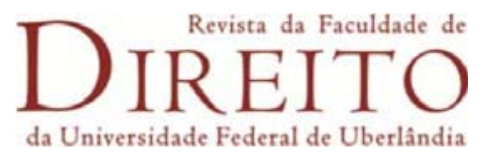

GEBHART, Andrew. Everything you need to know about the Amazon Echo. C-NET, 21 set. 2018. Disponível em: https://www.cnet.com/home/smart-home/amazon-echo-alexaeverything-you-need-to-know/. Acesso em: 21 jan. 2021

GOOGLE. Discover what your Assistant can do. s/d. Disponível em: https://assistant.google.com/intl/en_uk/\#?modal_active=none. Acesso em: 10 AGO. 2021

KLEIN VIEIRA, Luciane, La hipervulnerabilidad del consumidor transfronterizo y la funcíon material del Derecho Internacional Privado. $1^{a}$ Ed. - Ciudad Autónoma de Buenos Aires : La Ley, 2017.

KLEIN VIEIRA, Luciane; CARDOSO SQUEFF, Tatiana. A proteção internacional do consumidor turista na agenda da Conferência da Haia de Direito Internacional Privado e do MERCOSUL: avanços e retrocessos. RDC - Revista de Direito do Consumidor, vol. 130/2020, p. 237 - 272, Jul - Ago / 2020.

LEITÃO, Miriam. Saga Brasileira: a longa luta de um povo por sua moeda. Rio de Janeiro: Record, 2011.

LIMA MARQUES, Claudia. Esforços para incluir o tema da proteção do turista na Agenda de Trabalho da Conferência da Haia e a proposta brasileira de Convenção de Cooperação em matérias de proteção dos visitantes e turistas estrangeiros". RDC - Revista de Direito do Consumidor, vol. 90/2013, p. 39 - 64, Nov - Dez / 2013.

LIMA MARQUES, Claudia. Lei mais favorável ao consumidor e o Acordo do MERCOSUL sobre Direito aplicável em matéria de contratos internacionais de consumo de 2017. RDC Revista de Direito do Consumidor, vol. 121/2019, p. 419 - 457, Jan - Fev, 2019.

LIY, Macarena Vidal. Quince países de Asia acuerdan la mayor zona de libre comercio mundial. El País, Pequim, 05 nov. 2019. Disponível em: https://elpais.com/internacional/2019/11/04/actualidad/1572888525_052080.html Acesso em: 21 jan. 2021

MERCOSUL. Acuerdo del MERCOSUR sobre derecho aplicable en materia de contratos internacionales de consumo. 2017. Disponível em: www.cartillaciudadania.mercosur.int/oldAssets/uploads/67229_DEC_036-

\%202017_ES_Acuerdo\%20Inter\%20Consumo.pdf. Acesso em: 21 jan. 2021.

MEXICO. Informe Anual PROFECO 2018. Disponível em: https://www.gob.mx/cms/uploads/attachment/file/485958/INFORME_ANUAL_PROFECO_2 018.pdf. Acesso em 21 jan. 2021.

NACIONES UNIDAS. UNGCP. United Nations Guidelines for Consumer Protection (UNGCP) - atualizadas. Genebra, 26 jul. 1999. Disponível em: https://unctad.org/system/files/official-document/ditccplpmisc2016d1_en.pdf. Acesso em: 21 jan. 2021

NACIONES UNIDAS. United Nations Guidelines for Consumer Protection (UNGCP) - atualizadas. Genebra, 22 dez. 2015 (aprovadas pela Assembleia Geral da ONU em 2016 pela Res. 70/186). Disponível em: https:/unctad.org/system/files/officialdocument/ares70d186_en.pdf . Acesso em: 21 jan. 2021

NACIONES UNIDAS. General Assembly. Resolution 70/186: consumer protection. New York, 22 dec. 2015. Disponível em: https:/unctad.org/system/files/officialdocument/ares70d186_en.pdf . Acesso em: 21 jan. 2021

NETFLIX réduit les débits en Europe pour éviter une paralysie d'internet. La Presse, 19 mar. 2020. Disponivel em: https://www.lapresse.ca/affaires/techno/2020-03-19/netflixreduit-les-debits-en-europe-pour-eviter-une-paralysie-d-internet. Acesso em: 21 jan. 2021

OEA. Proposal by the member states for the 7th Inter-American Specialized Conference on Private Internacional Law - CIDIP VII. Topic I - Consumer Protection (Brazil, simplified version). Washington D.C., 10 nov. 2008. Disponível em: http://www.oas.org/dil/CIDIP- 
VII_working_doc_cp_simplified_version_final_brazilian_proposal.pdf . Acesso em: 10 ago. 2021

OECD. Consumer Policy Toolkit. Paris, 2010. Disponível em: https://www.oecd.org/sti/consumer/consumerpolicy-toolkit-9789264079663-en.htm. Acesso em: 21 jan. 2021.

OECD. Guidelines for Consumer Protection in the Context of Electronic Commerce. Paris, 2016. Disponível em: https://www.oecd.org/sti/consumer/34023811.pdf. Acesso em: 21 jan. 2021.

OECD. The role of online platforms in weathering the COVID-19 shock. Paris, 8 jan. 2021. Disponível em: https://www.oecd.org/coronavirus/policy-responses/the-role-of-onlineplatforms-in-weathering-the-covid-19-\%20shock-2a3b8434/. Acesso em 21 jan. 2021

O'FLAHERTY, Kate. Apple Siri Eavesdropping Puts Millions Of Users At Risk. Forbes, 28 jul. 2019. Disponível em: https://www.forbes.com/sites/kateoflahertyuk/2019/07/28/applesiri-eavesdropping-puts-millions-of-users-at-risk/?sh=1302d0c8a530. Acesso em: 21 jan. 2021

PAUWELYN, Joost. "Is It International Law Or Not and Does It Even Matter?" In: Joos Pauwelyn, Gaillard, Emmanuel. Legal Theory of Arbitration. Hague: Martinus Nijhoff, 2010.

PORTUGAL. Livro de Reclamações: Direção Geral do Consumidor. s/d. Disponível em: https://www.consumidor.gov.pt/livro-de-reclamacoes.aspx Acesso em 21. Jan. 2021

RIEFA, Christine; HUNTER, Julie. The challenges of protecting consumers in Global market places. BEUC Vzbv, s/l, 2017. Disponível em: https://www.vzbv.de/sites/default/files/downloads/2017/11/08/17-11-08_brochure-vzbv-

beuclr3.pdf. Acesso em: 21. Jan. 2021.

ROBERTS, Simons. "Why the State". Singapore Symposium on Legal Theory, 2015.

SANTOS, Mirian. Por uma outra globalização: do pensamento único à consciência universal. 13ª ed. São Paulo: Editora Record, 2006.

SCHULTZ, Thomas. "Non-Analytical Obstacles to Stateless Law" North Carolina Journal of International Law, vol. 43, p. 182 et seq., 2018.

SCHULTZ, Thomas. "Of Correct Views on Law Without the State". Journal of International Dispute Settlement, vol. 6, n. 1, pp. 2-3, Mar. 2015.

SCHULTZ, Thomas. Transnational Legality: Stateless Law and International Arbitration. Oxford: OUP, 2014.

SCHULTZ, Thomas. "Private Legal Systems: What Cyberspace Might Teach Legal Theorists". Yale Journal of Law \& Technology, vol. 10, p. 151 et seq., 2008.

SCHULTZ, Thomas. "Connecting complaint filing processes to online resolution systems". Commercial Law Practitioner, vol. 10, n. 11, Dec. 2003.

SOO, Zen. Here's how China's new e-commerce law will affect consumers, platform operators. South China Morning Post. 1 jan. 2019. Disponível em: https://www.scmp.com/tech/apps-social/article/2180194/heres-how-chinas-new-e-commercelaw-will-affect-consumers-platform . Acesso em: 21 jan. 2021

UNCTAD. Manual on Consumer Protection. Genebra, 2017. Disponível em: https://unctad.org/en/PublicationsLibrary/ditccplp2017d1_en.pdf. Acesso em 21 jan. 2021.

UNCTAD. Information Economy Report 2015 Unlocking the Potential of ECommerce for Developing Countries. Genebra, 2015. Disponível em: https://unctad.org/system/files/official-document/ier2015_en.pdf. Acesso em: 21 jan. 2021.

UNIÃO EUROPEIA. Diretiva 2013/11/EU de 21 de maio de 2013 sobre ODR para litígios de consumo. 2013a.Disponível em: https:/eur-lex.europa.eu/eli/dir/2013/11/oj . Acesso em: 10 ago. 2021. 
UNIÃO EUROPEIA. Regulation 524/2013 of 21 May 2013 on online dispute resolution for consumer disputes. 2013b. Disponível em: https://eurlex.europa.eu/legalcontent/EN/TXT/PDF/?uri=CELEX:32013R0524\&from=EN. Acesso em: 10 ago. 2021.

UNIAO EURIPEIA. Online Dipsute resolution. s/d. Disponível em: https://ec.europa.eu/consumers/odr/main/index.cfm?event=main.home2.show\&lng=EN. Acesso em: 08 ago 2021.

Artigo recebido em: 08/02/2021 